\title{
Knowledge, practice and attitude regarding gynecological examination among maternity nurses in Benha university hospital
}

\author{
Mona M. Mahrous ${ }^{1}$, Soad A. Ramadan ${ }^{2}$, Aziza I. Mohamed ${ }^{3}$, Hemmat \\ M. El-Banna ${ }^{4}$ \\ ${ }^{1}$ Specialist nurse in ophthalmic benha hospital. Egypt, ${ }^{2}$ Assist. Prof \& Chairman of \\ Woman's Health and Obstetric Nursing, Faculty of Nursing, Banha University. Egypt, \\ ${ }^{3}$ Assistant Professor of Woman's Health and Obstetric Nursing, Faculty of Nursing, \\ Banha University. Egypt, ${ }^{4}$ Lecturer of Woman's Health and Obstetric Nursing, Faculty of \\ Nursing, Banha University. Egypt
}

\begin{abstract}
Gynecological examination is crucial for protecting the reproductive health of women. The purpose of this study was to assess knowledge, practice and attitude regarding gynecological examination among maternity nurses at banha university hospital. The study was conducted in obstetrics and gynecology department at banha university hospital . The design of this study was a descriptive research design. A convenient sample included 50 nurses were recruited in the study. Three instruments were utilized for data collection, interviewing questionnaire sheet, observation check list and modified Likert scale. The result of this study revealed that $28 \%$ of studied nurses had adequate knowledge, $34 \%$ of them had positive attitude and $48 \%$ of them had competent performance regarding gynecological examination. Conclusion, this study concluded that less than three quarters of studied nurses had inadequate knowledge regarding gynecological examination and less than half of studied nurses had uncertain attitude, also more than half of studied nurses had incompetent performance of clinical gynecological examination. Therefore, it is recommended that national educational programs and workshops should be designed to promote knowledge, practices and attitudes of maternity nurses regarding gynecological examination.
\end{abstract}

Key words: gynecological, examination, knowledge, practice, attitude.

\section{INTRODUCTION}

Gynecological examination is a routine procedure used to assess the well-being of the female patients' lower genito-urinary tract. This is done as part of a usual health screening and prevention tool, and is an element of the total health care for the female patient (Abdelati \& Hasaneen, 2012).

Gynecology is health care for the female body, focusing on the sexual and reproductive organs. Appropriate gynecological care helps in prevent many undesired cancers, diseases and other illnesses by allowing for early detection. Early detection is essential for effective preventative measures and treatment (Close et al., 2016).
Regular gynecological examinations are an essential part of any woman's health care. Ideally, women should have a woman's health exam before they begin sexual activity. All women should have their first woman's health exam by age 21 . If a woman detects any pain or menstrual irregularities, an earlier medical exam is also advised. The exam should be done once a year unless the clinician advises differently (Massad et al, 2013).

\section{PURPOSE}

To assess knowledge, practices and attitudes regarding gynecological examination among maternity nurses at benha university hospital. 

nurses in benha university hospital.

\section{Study questions:}

- What is the level of maternity nurses' knowledge regarding gynecological examination?

- What is the level of maternity nurses' practice regarding gynecological examination?

- What is the level of maternity nurses' attitude regarding gynecological examination?

\section{METHODS}

1- Research design: A descriptive design has been adopted to fulfill the aim of the present study.

2- Research setting: This study was conducted in obstetrics and gynecology department at Banha university hospital

3- Sampling: A convenient sample.

Size and technique: all available nurses during time of data collection from the previous mentioned setting were included in the study $(\mathrm{n}=50)$.

4- Instruments: three instruments were utilized for data collection.

Instrument one: interviewing Selfadministrated questionnaire. It was designed by researcher and included Socio- demographic data such as age, level of education, years of experience, social status and residence ....., etc. It also included assessing knowledge of nurses regarding gynecological examination e.g definition, purpose and indications.

Instrument two: Modified likert scale. It was developed by the researcher after a review of literature about Afifi, (2015)

Instrument three: Observation checklist: Clinical gyneacological examination checklist. This checklist was adopted from El Shafey, (2017).

\section{Procedure:}

1- An official letter was presented from the Dean of Beha Faculty of Nursing that contained the title and objectives of the study were provided to the director of Banha University Hospital to obtain the official agreement to conduct the study.

2- The data collection instrument was developed after a review of past and current local and international related literature including books, articles, periodicals and magazines to get acquainted with the various aspects of the research problem and to acquire the needed knowledge to conduct the study and prepare the necessary instrument.

3- For validity assurance, the instruments were assessed by three experts in obstetric and gynecological nursing field. The questionnaire was modified according to the expert's comments and recommendations.

4- The reliability of the instruments was tested to determine the extent to which items in the questionnaire were related each other by Cronbach alpha 0.76 . Reliability for attitude was Cronbach alpha 0.81 .

5- A pilot study was carried for $10 \%$ of the total sample (5) nurses to evaluate the simplicity, clarity and applicability of study instruments and the time needed to fill in the questionnaire. According to the results of the pilot study, simple necessary modifications were done in the form of adding and omitting some questions and pilot study were excluded from main study sample.

6- For ethical consideration an oral consent was obtained from maternity nurses before any data collection. This consent was 
obtained after explaining the aim and nature of the study. The study was voluntary, harmless, anonymous, and confidentiality of response would be respected. All nurses had the full rights to refuse to participate in the study and withdraw at any time.

7- Data was collected over a period of 6 months starting from May to October 2017.

8- All studied maternity nurses were interviewed using instrument one. Then, instrument two and three were used and all data was collected through personal interviews.

\section{DATA ANALYSIS:}

The data was organized, categorized and tabulated by using appropriate statistical methods. Data entry and statistical analysis were done by using statistical package for a social science (SPSS version 22.0) .

\section{RESULTS}

Table 1 reveals that $52 \%$ of the studied nurses aged (20-30) years with mean age of $30.52 \pm 6.87,76 \%$ of them were married and $70 \%$ of them lived in rural areas. Moreover, 52\% of them had bachelor of nursing and $62 \%$ of the studied nurses had $>5$ years of experience. Also, $96 \%$ of them hadn't taken any special scientific sessions regarding gyneacological examination.

Table 2 indicates that $78 \%$ of the studied nurses defined the gyneacological examination as an examination is necessary to be performed once a year, $74 \%$ of them added that time of the gyneacological examination was two weeks after the menstrual cycle. Moreover, $76 \%$ of the studied nurses had incorrect answers regarding the frequency of gyneacological examinations as Every 6 years. Also, $70 \%$ of them had incorrect answer regarding the proper age for gyneacological examination as atmenopause.

Table 3 Reveals that $92 \%$ of the studied nurses agreed that the sooner the examination was, the sooner the disease detection. In addition $82 \%$ of them agreed that the gyneacological examination was important for married or unmarried woman. Also, $60 \%$ of studied nurses were uncertain about performing gyneacological examination because of the fear from the result of the examination. Moreover 50\% of them disagreed that gyneacological examination may transmit of infection and only $8 \%$ of them disagreed that women should perform regular gyneacological examination.

Table 4 Includes that, all of the studied nurses made sure for good lightening with no glares of shadow and $98 \%$ of them asked the woman to empty the bladder before starting the procedure, on the other hand, $96 \%$ of the studied nurses didn't offered the woman a seat and didn't explained to the woman what is going to be done and obtained the consent to perform the procedures. Moreover, $94 \%$ of them didn't greeted the woman and the companion respectfully and with kindness, and didn't asked woman for the menstrual history before the examination.

Table 5 Clarifies that there was a negative correlation between studied nurses' total knowledge and practice score. On the other hand, there was a highly statistical positive correlation between studied nurses total knowledge and attitude score. 
Knowledge, practice and attitude regarding gynecological examination among maternity nurses in benha university hospital.

Table (1): Distribution of the studied nurses regarding their Socio- demographic data $(\mathbf{n}=50)$

\begin{tabular}{|c|c|c|}
\hline \multicolumn{3}{|c|}{ Socio- demographic data } \\
\hline$\overline{\text { Item }}$ & $\overline{\text { No }}$ & $\%$ \\
\hline \multicolumn{3}{|l|}{ Age in years } \\
\hline $20-$ & 26 & 52.0 \\
\hline $30-$ & 17 & 34.0 \\
\hline $40-50$ & 7 & 14.0 \\
\hline \multicolumn{3}{|l|}{ Mean \pm SD $=30.52 \pm 6.87$} \\
\hline \multicolumn{3}{|l|}{ Residence } \\
\hline Urban & 15 & 30.0 \\
\hline Rural & 35 & 70.0 \\
\hline \multicolumn{3}{|l|}{ Marital status } \\
\hline Single & 12 & 24.0 \\
\hline Married & 38 & 76.0 \\
\hline \multicolumn{3}{|l|}{ Educational level } \\
\hline Diploma & 19 & 38.0 \\
\hline A technical institute & 5 & 10.0 \\
\hline Bachelor of Nursing & 26 & 52.0 \\
\hline \multicolumn{3}{|l|}{ Years of experience } \\
\hline Less than one year & 7 & 14.0 \\
\hline from 1 year to 5 years & 12 & 24.0 \\
\hline$>5$ years & 31 & 62.0 \\
\hline \multicolumn{3}{|c|}{ Taking any special scientific sessions of gyneacological examination } \\
\hline Yes & 2 & 4.0 \\
\hline No & 48 & 96.0 \\
\hline
\end{tabular}

Table (2): Distribution of the studied nurses' general knowledge regarding gyneacological examination $(\mathbf{n}=\mathbf{5 0})$.

\begin{tabular}{|c|c|c|c|c|}
\hline \multirow{2}{*}{ Knowledge items } & \multicolumn{2}{|c|}{ Incorrect } & \multicolumn{2}{|c|}{$\overline{\text { Correct }}$} \\
\hline & No & $\%$ & No & $\%$ \\
\hline \multicolumn{5}{|c|}{ Definition of gyneacological examination } \\
\hline An examination is necessary to be performed once a year. & 11 & 22.0 & 39 & 78.0 \\
\hline Regular routine procedure for women to examine female genitalia. & 22 & 44.0 & 28 & 56.0 \\
\hline An examination done for the woman to follow up pregnancy women. & 16 & 32.0 & 34 & 68.0 \\
\hline $\begin{array}{l}\text { A doctor's examination is used to early detection of gyneacological } \\
\text { diseases. }\end{array}$ & 32 & 64.0 & 18 & 36.0 \\
\hline \multicolumn{5}{|l|}{ Times of gyneacological examination } \\
\hline 1-Just before the menstrual cycle. & 25 & 50.0 & 25 & 50.0 \\
\hline 2-During the menstrual cycle. & 27 & 54.0 & 23 & 46.0 \\
\hline 3-Immediately after the end of the menstrual cycle. & 20 & 40.0 & 30 & 60.0 \\
\hline 4-Two weeks after the menstrual cycle. & 13 & 26.0 & 37 & 74.0 \\
\hline \multicolumn{5}{|l|}{ Frequency of gyneacological examinations } \\
\hline 1-Annually (once every year). & 27 & 54.0 & 23 & 46.0 \\
\hline 2-Monthly (once per month). & 20 & 40.0 & 30 & 60.0 \\
\hline 3-Every three months. & 28 & 56.0 & 22 & 44.0 \\
\hline 4-Every 6 years. & 38 & 76.0 & 12 & 24.0 \\
\hline \multicolumn{5}{|l|}{ Proper age for gyneacological examination } \\
\hline 1-Between the age of thirteen and fifteen years. & 18 & 36.0 & 32 & 64.0 \\
\hline 2-At the age of fertility. & 27 & 54.0 & 23 & 46.0 \\
\hline 3-At menopause. & 35 & 70.0 & 15 & 30.0 \\
\hline 4-When sexual intercourse is started. & 21 & 42.0 & 29 & 58.0 \\
\hline
\end{tabular}

Table (3): Distribution of the studied staff nurses' attitude regarding gyneacological examination $(n=50)$. 
Knowledge, practice and attitude regarding gynecological examination among maternity nurses in benha university hospital.

\begin{tabular}{|c|c|c|c|c|c|c|}
\hline \multirow{2}{*}{ Attitude } & \multicolumn{2}{|c|}{ Disagree } & \multicolumn{2}{|c|}{ Uncertain } & \multicolumn{2}{|c|}{ Agree } \\
\hline & No & $\%$ & No & $\%$ & No & $\%$ \\
\hline $\begin{array}{l}\text { 1) Women should perform regular gynecological } \\
\text { examinations. }\end{array}$ & 4 & $8.0 \%$ & 7 & $14.0 \%$ & 39 & $78.0 \%$ \\
\hline $\begin{array}{l}\text { 2) The sooner the examination was, the sooner the disease } \\
\text { detection. }\end{array}$ & 1 & $2.0 \%$ & 3 & $6.0 \%$ & 46 & $92.0 \%$ \\
\hline $\begin{array}{l}\text { 3) The best time to the gynecological examination after } \\
\text { the end of the menstrual cycle. }\end{array}$ & 3 & $6.0 \%$ & 18 & $36.0 \%$ & 29 & $58.0 \%$ \\
\hline $\begin{array}{l}\text { 4) Gynecological examination may be lead } \\
\text { transmission of infection. }\end{array}$ & 25 & $50.0 \%$ & 18 & $36.0 \%$ & 7 & $14.0 \%$ \\
\hline $\begin{array}{l}\text { 5) The incidence of cancers of the reproductive system is } \\
\text { because of the shame and fear of women to do } \\
\text { gynecological examination. }\end{array}$ & 20 & $40.0 \%$ & 20 & $40.0 \%$ & 10 & $20.0 \%$ \\
\hline $\begin{array}{l}\text { 6) One of the reasons why women don't performed } \\
\text { gynecological examination is the fear of the results. }\end{array}$ & 10 & $20.0 \%$ & 30 & $60.0 \%$ & 10 & $20.0 \%$ \\
\hline $\begin{array}{l}\text { 7) One of the reasons why virgins have not examined } \\
\text { gynecological diseases is that most doctors are men, not } \\
\text { women. }\end{array}$ & 16 & $32.0 \%$ & 19 & $38.0 \%$ & 15 & $30.0 \%$ \\
\hline $\begin{array}{l}\text { 8) Gynecological examination is a painful procedure for } \\
\text { women. }\end{array}$ & 5 & $10.0 \%$ & 26 & $52.0 \%$ & 19 & $38.0 \%$ \\
\hline $\begin{array}{l}\text { 9) Fear of gynecological examination may cause problems } \\
\text { during intercourse. }\end{array}$ & 15 & $30.0 \%$ & 16 & $32.0 \%$ & 19 & $38.0 \%$ \\
\hline $\begin{array}{l}\text { 10) The gynecological examination is important for } \\
\text { married or unmarried woman that faces women's } \\
\text { problems. }\end{array}$ & 1 & $2.0 \%$ & 8 & $16.0 \%$ & 41 & $82.0 \%$ \\
\hline $\begin{array}{l}\text { 11) The gynecological examination may lead to the early } \\
\text { detection of cancers of the reproductive system. }\end{array}$ & 0 & 0.0 & 11 & $22.0 \%$ & 39 & $78.0 \%$ \\
\hline $\begin{array}{l}\text { 12) Shyness from the gynecological examination may } \\
\text { lead woman to not turnout on conducting the } \\
\text { examination. }\end{array}$ & 10 & $20.0 \%$ & 13 & $26.0 \%$ & 27 & $54.0 \%$ \\
\hline
\end{tabular}

Table (4): Distribution of the studied nurses' practices before the gyneacological examination $(\mathbf{n}=50)$.

\begin{tabular}{|c|c|c|c|c|}
\hline \multirow{2}{*}{ Practice } & \multicolumn{2}{|c|}{ Not done } & \multicolumn{2}{|c|}{ Done } \\
\hline & No & $\%$ & No & $\%$ \\
\hline \multicolumn{5}{|l|}{-Before examination } \\
\hline 1-Greet the woman and her companion respectfully and with kindness. & 47 & 94.0 & 3 & 6.0 \\
\hline 2-Offer the woman a seat. & 48 & 96.0 & 2 & 4.0 \\
\hline 3-Interview the woman and take complete history & 45 & 90.0 & 5 & 10.0 \\
\hline 4-Calm woman and relief fear and anxiety & 17 & 34.0 & 33 & 66.0 \\
\hline $\begin{array}{l}\text { 5-Explain to the woman what is going to be done and obtain her consent to } \\
\text { perform the procedures. }\end{array}$ & 48 & 96.0 & 2 & 4.0 \\
\hline 6-Ask the woman to empty her bladder before starting the procedures. & 1 & 2.0 & 49 & 98.0 \\
\hline 7-Listen to her attentively, and respond to her questions and concerns. & 18 & 36.0 & 32 & 64.0 \\
\hline 8-Provide continual emotional support and reassurance, as possible. & 4 & 8.0 & 46 & 92.0 \\
\hline $\begin{array}{l}\text { 9-Use understandable language when asking about sensitive behaviors or } \\
\text { feelings }\end{array}$ & 42 & 84.0 & 8 & 16.0 \\
\hline $\begin{array}{l}\text { 10-Use active listening techniques: eye contact, non-verbal cues, } \\
\text { paraphrase/summarize patient concerns }\end{array}$ & 46 & 92.0 & 4 & 8.0 \\
\hline 11-Ask woman for her menstrual history. & 47 & 94.0 & 3 & 6.0 \\
\hline L2-Prepare the woman for physical examination. & 34 & 68.0 & 16 & 32.0 \\
\hline $\begin{array}{l}\text { 13-Make sure that there is good light. There should be no glares or } \\
\text { shadows. }\end{array}$ & & & 50 & 100.0 \\
\hline 14-Close windows and Keep privacy of the client to undress, underwear. & 45 & 90.0 & 5 & 10.0 \\
\hline 15-Take woman to suitable bed for examination. & 2 & 4.0 & 48 & 96.0 \\
\hline
\end{tabular}

Table (5): correlation coefficient between studied nurses' total knowledge, attitude and practice scores regarding gyneacological examination $(n=50)$. 
Knowledge, practice and attitude regarding gynecological examination among maternity nurses in benha university hospital.

\begin{tabular}{||c|c|c|c|c|}
\hline Items & Correlation test & Total knowledge & Total attitude & Total practice \\
\hline \multirow{2}{*}{ Total knowledge } & $\mathbf{r}$ & 1 & $.439^{* *}$ & -.192 \\
\cline { 2 - 5 } & $\mathbf{p}$-value & & .001 & .182 \\
\hline \multirow{2}{*}{ Total attitude } & $\mathbf{r}$ & $.439^{* *}$ & 1 & -.258 \\
\cline { 2 - 5 } & $\mathbf{p}-v a l u e$ & .001 & & .070 \\
\hline \multirow{2}{*}{ Total practice } & $\mathbf{r}$ & -.192 & -.258 & 1 \\
\cline { 2 - 5 } & $\mathbf{p}-$ value & .182 & .070 & \\
\hline
\end{tabular}

$* \mathrm{P}<0.05 \quad * * \mathrm{P}<0.001$

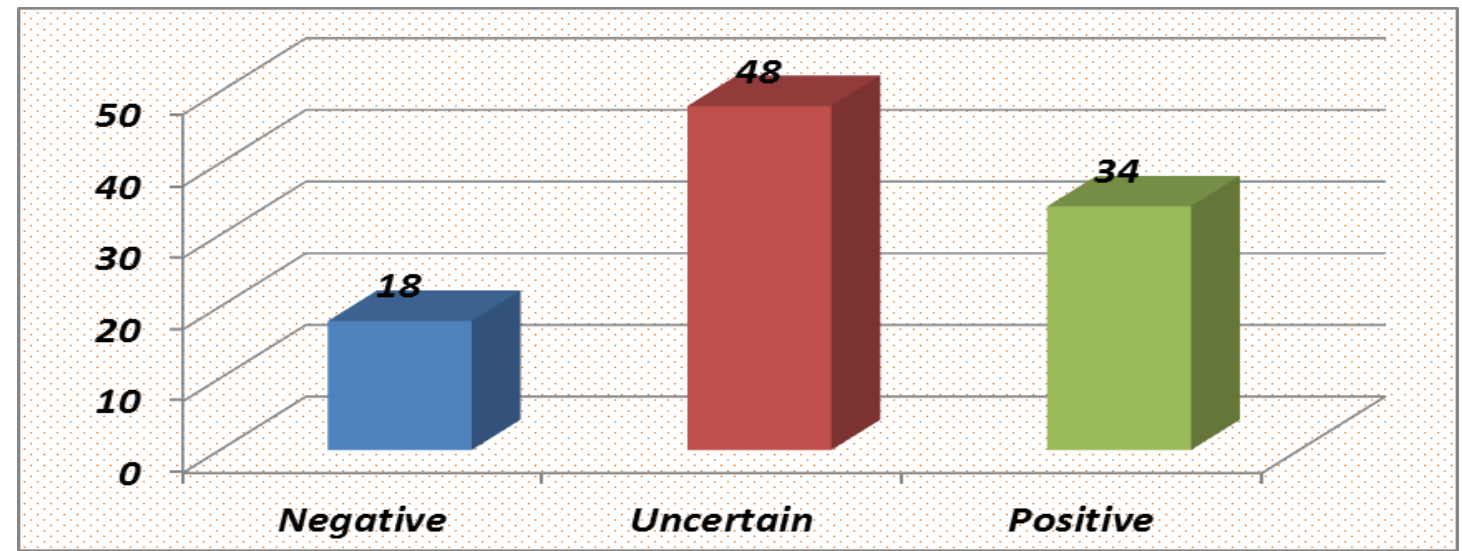

Figure (1): Percentage distribution of total attitude score of the studied staff nurses regarding gyneacological examination $(n=50)$

\section{Discussion}

The gynecological examination is an essential part of gynecological care and is the most commonly performed procedure in gynecological practice. A large number of women in the world will have a gynecological examination at some time in their lives, and some may undergo several examinations during their lifetime. This examination may induce many negative feelings, such as embarrassment, shame and anxiety (Yanikkerem et al, 2015) and proper gynecological care helps to prevent many undesired cancers, diseases and other illnesses by allowing for early detection. Early detection is essential for effective preventative measures and treatment (Close et al, 2016). Moreover many studies clarified that health care provider had a pivotal role regarding reducing anxiety, stress and disruptions (Aktas et al, 2017), (Altay \& Kefeli, 2017).

So the aim of the present study is to assess knowledge, practice and attitude toward gynecological examination among nurses in obstetrics and gynecological department. This aim was significantly achieved through a descriptive study design that answered the research questions (What is the level of maternity nurses' knowledge regarding gynecological examination? What is the level of maternity nurses' practice regarding gynecological examination? What is the level of maternity nurses' attitude regarding gynecological examination?)

Concerning the age of maternity nurses in this study (Table 1), the findings of the present study clarified that, more than half of the studied nurses were aged (20-30) years old. This result was supported with Al-Husaunawy, (2015) in the study about evaluate nurses' knowledge and practical of electrocardiogram toward adolescent patient who stated that more than half of nurses were aged (21-27) years old. On the other hand, the findings were disagreement with Ribeiro et al, (2013) in the study about assess student nurses' knowledge, attitude and practice regarding the 


\section{Knowledge, practice and attitude regarding gynecological examination among maternity nurses in benha university hospital.}

papanicolaou examination who stated that nearly half of student nurses were aged (20 $-22)$.

Regarding the educational level and the years of experience of studied nurses, the same table showed that more than half of them had bachelor of nursing and more than half of the studied nurses had more than 5 years of experience. This result was in contrast with Gebrie et al, (2015) in the study about assess knowledge, preventive practice and associated factors of female nurses' towards cervical cancer in the selected government hospitals in Addis Ababa, Ethiopia" who stated that over half of the nurses were diploma holders and the majority of them had less than 5 years work experience.

Concerning studied nurses' general knowledge regarding gynecological examination (table 2), the present study found that more than two thirds of the studied nurses had correct answer about the definition of gynecological examination and had incorrect answer regarding the proper age for gynecological examination as at menopause. This result was in agreement with Ricciard (2013) who stated that there was no preference time for the woman to have their first gynecological examination. The decision to perform gynecological examination should be based on the age of the woman, her history and presenting symptoms and considerations of the additional value a pelvic examination will add in making a diagnosis. In congruent with the results, (Committee on Gynecologic Practice, 2012) indicated that the young woman must have their first gynecological examination when they are around the age of 18 years old. However, it was recommended earlier than 18 if they are sexually active or have a medical problem requiring gynecological examination. After the first examination, they should perform exams once a year especially if they are sexually active. A yearly examination can detect any abnormalities which may have developed and ensure early treatment.

The finding of current study showed that more than three quarters of the studied nurses had incorrect answer regarding the Frequency of gynecological examinations. Which it disagreement with, the American College of Obstetricians and Gynecologists suggests that the annual visit has value, and recommends annual examination for asymptomatic adult women (from age 21 on) which should include internal bimanual pelvic and speculum examinations. (Committee on Gynecologic Practice, 2012). Several obstetricians and gynecologists in the U.S. believe that longer intervals between routine examinations would have negative repercussions for patients and medical practice (Henderson et al, 2014). There by, this incorrect knowledge may cause women liable to serious health problems.

The present study showed that (table 3), the majority of the studied nurses agreed that the sooner the examination the earlier the disease detection. The gynecological examinations are important for married or unmarried women especially women who suffer from gynecological problems. More than three quarters of nurses agreed that gynecological examination may lead to the early detection of cancers in the reproductive system. Therefore, women should perform regular gynecological examinations. On the other hand, more than half of studied nurses were uncertain that women may not perform gynecological examination because of the fear from the results of the examination. The uncertain attitude of the studied nurses might be related to lack of health educational programs that could play an important role in developing the attitude of nurses regarding the gynecological examination.

Nurses play an important part in gynecological examination especially before examination, nurse should explained the procedure for woman and 


\section{Knowledge, practice and attitude regarding gynecological examination among maternity nurses in benha university hospital.}

how they are performed and also specific instructions necessary for appropriate preparation. Also during examination, the nurse should take complete history, reassure woman during procedure, and perform steps of nursing procedure. While after examination, the nurse should discuss the results of the examination, arrange for any follow up or consultation needed and final ask any further questions. (Metzlerlisa, 2013).

The present study showed that (table 4), the majority of the studied nurses neither offered women a seat nor explained to the woman what was going to be done. Moreover, they did not obtain the consent to perform the procedures.

In this respect, the findings of present study agreed with El Shafei N.M, (2017) who stated that, the majority of studied women didn't know them what was going to be done. The results of this study agreed with the result of a study about knowledge and attitude for newly married women toward their first gynecological examination by Abdelati \& Hasaneen, (2012) they didn't receive explanation about what was going to be done, only $17 \%$ of women had explaination about first gynecological examination.

So, from the researcher point of view this could lead to increased fear and anxiety.

In relation to nurses' performance before, during and after gynecological examination, the present study showed that the majority of the studied nurses had not taken from woman the history before starting the examination. These results disagreeded with Abdelati \& Hasaneen, (2012) and El Shafei N.M, (2017) they demonstrated that history was obtained from the majority of the studied women before beginning the examination. Also, the majority of the studied nurses asked women to empty the bladder before starting the procedure. This result was in agreement with Abdelati \& Hasaneen, (2012)
For nurses performance related to reducing women anxiety the present study revealed that the necessary measures to reduce patient's anxiety are not fully implemented, especially in regard to tolerance, patient privacy and personal data protection. The majority of studied nurses didn't explain to women what was going to be done and didn't obtain their consent to perform the procedures, didn't close windows, keep privacy of the client to undress.

This result was in the same line with a study done to assess Importance of demographic characteristics and nurses' role in women's perceptions and experiences gynecological examination by Zaic, (2015). He demonstrated that patient's privacy was often violated due to inappropriate separation of the examination and dressing room. Some other patients commented that health providers paid no attention to the problem of privacy. Above all, protection of privacy and confidentiality is essential to the trusting relationship between nurses and patients.

For correlation coefficiency between studied staff nurses' total knowledge, attitude and practices regarding gyneacological examination (table 5), the result of the current study revealed that a highly positive correlation between studied staff nurses total knowledge and attitude score. This could mean that knowledge could contribute to positive attitude chance.

\section{Conclusion}

In the light of the results of the present study, it could be concluded that; less than three quarters of studied nurses had inadequate knowledge regarding gynecological examination and less than half of studied nurses had uncertain attitude. Also more than half of studied nurses had incompetent performance of clinical gynecological examination.

\section{Recommendations}




\section{Knowledge, practice and attitude regarding gynecological examination among maternity nurses in benha university hospital.}

In the light of the current study findings, the following recommendations are suggested:

- Educational programs regarding gynecological examination are recommended for the nurses working in obstetrics and gynecology department.

- Workplace training regarding gynecological examination should be available for all nurses to improve their practice.

Further study need to be performed:This study was needed to be implanted on a larger sample of nurses for generalizability purpose

\section{References}

Abdelati, I. H., \& Hasaneen, N. M., (2012). Assessment of Knowledge and Attitude for Newly Married women toward their First Gynecological Examination Procedures in Al-Jouf City. Journal of American Science, 8(12).

Afifi, O. A. W., (2015). Knowledge, attitude and practice of nurses regarding early detection of breast and cervical cancer. Master thesis, faculty of nursing, Benha University. pp86,100

Aktas, D., Kumas, M. B., Odabasioglu, B. S., \& Kaya, A., (2017). Effect of a Special Examination Gown and Nature-Based Sounds on Anxiety in Women Undergoing a Gynecological Examination. Clinical Nursing Research, 1054773816686475.

Close, R. J., Sachs, C. J., \& Dyne, P. L. (2016).Reliability of bimanual pelvic examinations performed in emergency departments. Western Journal of Medicine, 175(4), pp 240.

Committee on Gynecologic Practice, (2012). Committee opinion No. 534: well-woman visit. Obstetrics and gynecology, 120(2 Pt 1), 421.
El Shafe, N. M. A., (2017). Assessment of care given to women undergoing gynecological examination. Master thesis, Faculty of nursing, Benha University. pp 4, 61-65

Henderson, T.J., Yu, M.J., Harper, C.C. \& Sawaya, F.G., (2014).U.S. clinicians' perspectives on less frequent routine gynecologic examinations. Preventive Medicine, 62, pp. 49-53. http://dx.doi.org/10.1016/j.ypmed.201 4.02.004 PMid: 24518004

Massad, L. S., Einstein, M. H., Huh, W. K., Katki, H. A., Kinney, W. K., Schiffman, M. \& Lawson, H. W., (2013). 2012 updated consensus guidelines for the management of abnormal cervical cancer screening tests and cancer precursors. Journal of Lower Genital Tract Disease, 17, S1S27.

Matzlerlisa, M., (2013). Walking into woman hood preparing you daughter for her first gynecological, visit, http://teenagerstoday.com pp1, 4 .

Ricciardi R., (2013). First pelvic examination in the adolescent. Nurse Practice Forum.;11(3),pp161-169.

Yanikkerem, E., Özdemir, M., Bingol, H., Tatar, A., \& Karadeniz, G,. (2015). Women's attitudes and expectations regarding gynaecological examination. Midwifery, 25(5),pp 500-508.

Zaic, D., \& Prosen, M,. (2015). Importance of demographic characteristics and nurses' role in women's perceptions and experiences of gynecological examination/Pomendemografskih znacilnosti in vloge medicinske sestre pri dozivljanju zensk ob ginekoloskem pregledu. Obzornik Zdravstvene Nege, 49(2),pp90. 